\title{
8
}
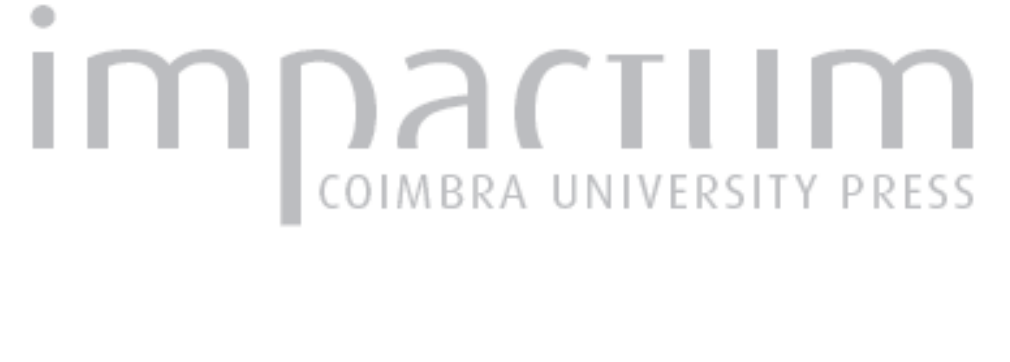

\section{Discussão sobre risco ambiental a partir de pesquisas desenvolvidas na escola básica e em comunidade localizada em área de risco. Belo Horizonte/Brasil}

Autor(es): $\quad$ Souza, Carla Juscélia de Oliveira

Publicado por: Associação Portuguesa de Riscos, Prevenção e Segurança; Imprensa

URL

persistente: da Universidade de Coimbra

DOI: DOI:https://doi.org/10.14195/1647-7723_23_9

Accessed : $\quad$ 26-Apr-2023 10:57:35

A navegação consulta e descarregamento dos títulos inseridos nas Bibliotecas Digitais UC Digitalis, UC Pombalina e UC Impactum, pressupõem a aceitação plena e sem reservas dos Termos e Condições de Uso destas Bibliotecas Digitais, disponíveis em https://digitalis.uc.pt/pt-pt/termos.

Conforme exposto nos referidos Termos e Condições de Uso, o descarregamento de títulos de acesso restrito requer uma licença válida de autorização devendo o utilizador aceder ao(s) documento(s) a partir de um endereço de IP da instituição detentora da supramencionada licença.

Ao utilizador é apenas permitido o descarregamento para uso pessoal, pelo que o emprego do(s) título(s) descarregado(s) para outro fim, designadamente comercial, carece de autorização do respetivo autor ou editor da obra.

Na medida em que todas as obras da UC Digitalis se encontram protegidas pelo Código do Direito de Autor e Direitos Conexos e demais legislação aplicável, toda a cópia, parcial ou total, deste documento, nos casos em que é legalmente admitida, deverá conter ou fazer-se acompanhar por este aviso.

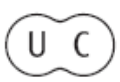




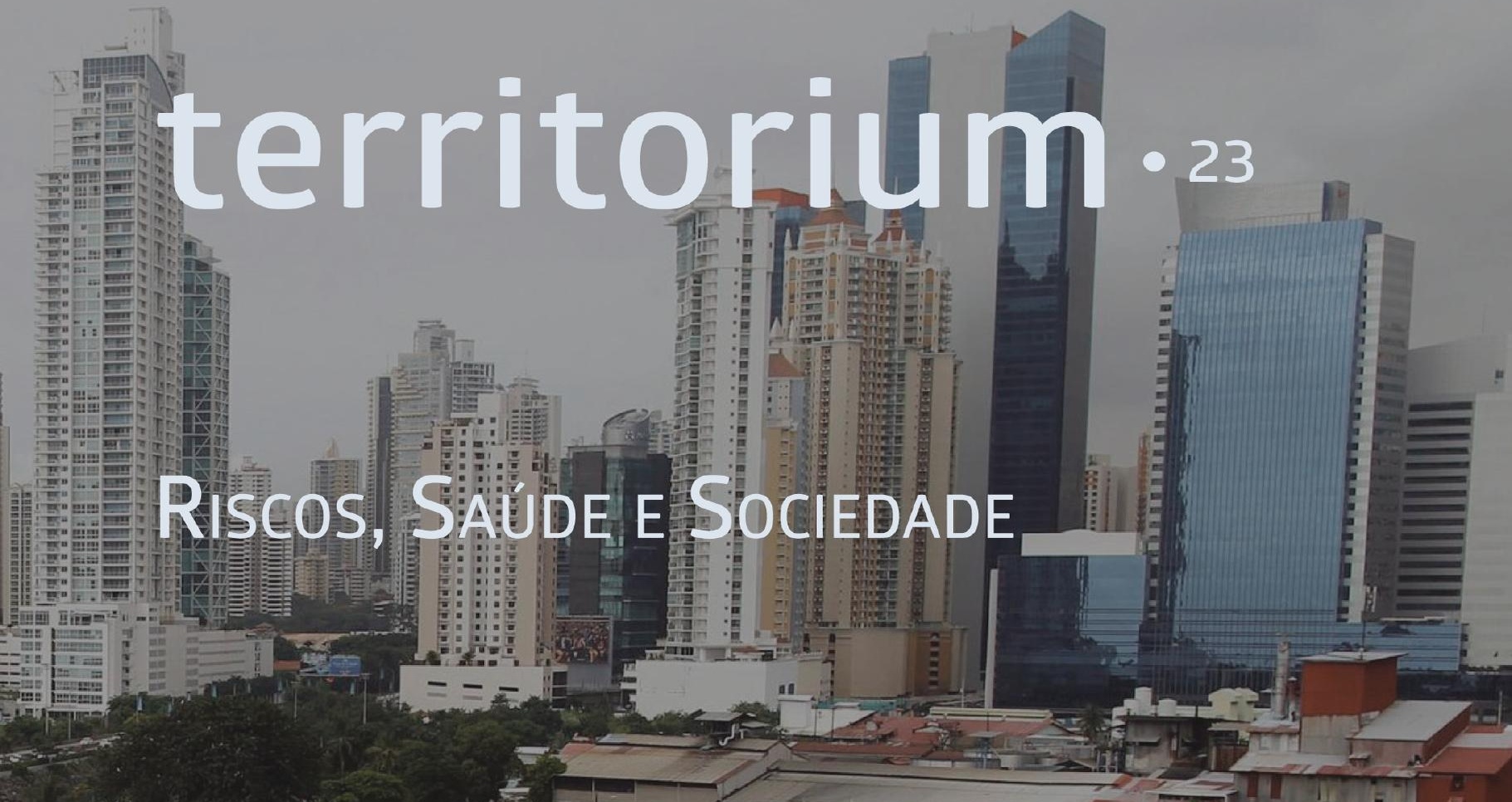

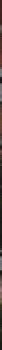

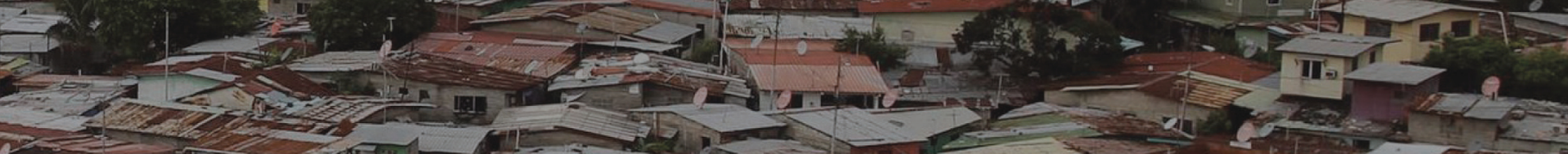

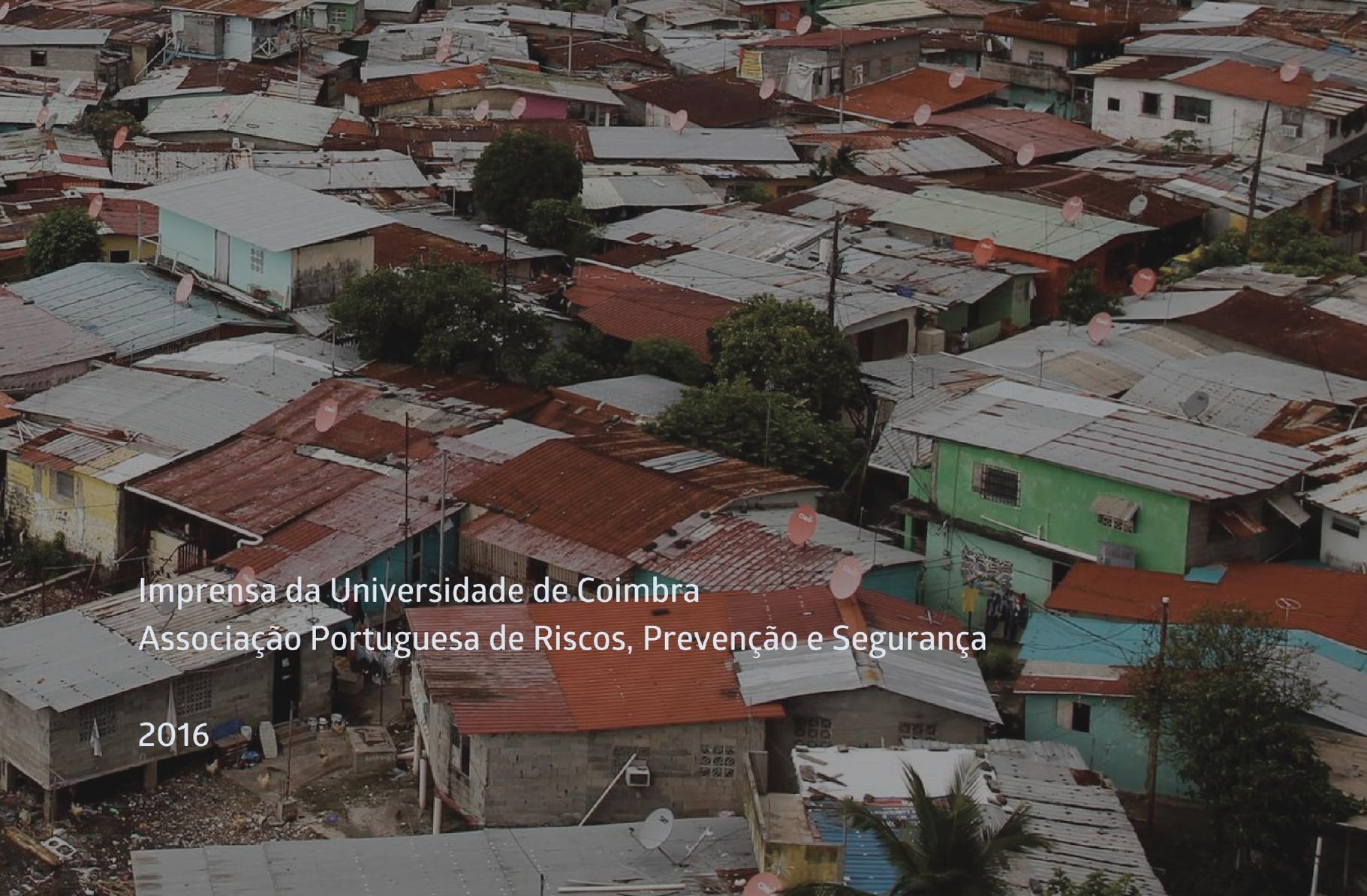




\section{DISCUSSÃO SOBRE RISCO AMBIENTAL A PARTIR DE PESQUISAS DESENVOLVIDAS NA ESCOLA BÁSICA E EM COMUNIDADE LOCALIZADA EM ÁREA DE RISCO. BELO HORIZONTE/BRASIL*}

\section{DISCUSSION ON ENVIRONMENTAL RISK FROM RESEARCH DEVELOPED IN SCHOOL AND COMMUNITY LOCATED AT A RISK AREA. BELO HORIZONTE/ BRAZIL}

Carla Juscélia de Oliveira Souza

Departamento de Geociências, Curso de Geografia Universidade Federal de São João del-Rei carlaju@ufsj.edu.br

\section{RESUMO}

Este trabalho apresenta e discute o tipo de abordagem e conteúdos referentes a riscos ambientais presentes em três Trabalhos de Conclusão de Curso (TCC's). Na discussão foram considerados os conceitos vulnerabilidade, perigo e risco na análise qualitativa do conteúdo dos trabalhos. A questão do risco foi considerada a partir de abordagens referentes à percepção ambiental, à concepção de riscos e dos saberes escolar.

Palavras-chave: Risco, escola e geografia.

\section{ABSTRACT}

This paper presents and discusses approach and content related to environmental hazards present in three surveys of undergraduate. The discussion considered the concepts vulnerability, hazard and risk in the qualitative analysis of the content of the work. The issue of risk was considered from approaches related to environmental perception, design risk and school knowledge.

Keywords: Risk, school and geography.

\section{RESUMEN}

Debate sobre Riesgo Ambiental desarrollado en una Investigación Básica de la Escuela y Comunidad ubicada en una Zona de Riesgo (Belo Horizonte/ Brasil) - Este artículo presenta y discute el enfoque y los contenidos relacionados con riesgos ambientales presentes en tres trabajo de conclusión de curso. La discusión considera el concepto de vulnerabilidad, peligro y riesgo en el análisis cualitativo del contenido de la obra. El tema del riesgo se consideró con base en enfoques relacionados con la percepción del medio ambiente, la concepción de riesgo y los conocimientos escolares.

Palabras clave: Riesgo, escuela, geografía.

\section{RESUMÉ}

Débat sur les risques environnementaux à partir de recherche menée dans une école de primaire communautaire située dans une zone de risque (Belo Horizonte / Brésil) - Cet article présente et discute de l'approche et du contenu lié aux risques environnementaux dans trois conclusions de cours. La discussion aborde le concept de vulnérabilité, le danger et le risque dans l'analyse qualitative du contenu des travaux. La question du risque a été considérée comme fondée sur la perception concernant les approches environnementales, la notion de risque et la connaissance de l'école.

Mots-clé: Risque, école, géographie.

* O texto deste artigo corresponde a uma comunicação apresentada no III Congresso Internacional, I Simpósio Ibero-Americano e VIII Encontro Nacional de Riscos, tendo sido submetido em 09-02-2015, sujeito a revisão por pares a 02-07-2015 e aceite para publicação em 31-03-2016.

Este artigo é parte integrante da Revista Territorium, n. ${ }^{\circ} 23,2016,{ }^{\circ}$ RIscos, ISSN: 0872-8941. 


\section{Introdução}

O trabalho compreende a análise conceitual dos termos área de risco ambiental e vulnerabilidade presentes em três trabalhos de conclusão de curso (TCC's), na área da Geografia, realizados no período de 2010 a 2011, no Centro Universitário de Belo Horizonte. A escolha desses trabalhos ocorreu devido aos assuntos contemplados nos mesmos - Saberes de geografia física no cotidiano da escola; Concepção de risco socioambiental entre alunos do ensino médio e Percepção ambiental da população da vila Bacuraus. 0 uso dos termos riscos, vulnerabilidade e áreas de riscos, entre trabalhos acadêmicos, no Brasil, é relativamente recente se considerado o contexto de acidentes e desastres de origem natural e ou ambiental. $\mathrm{E}$ em trabalhos que consideram a pesquisa na escola básica é, praticamente, ausente. Esse fato pode ser confirmado ao se investigar as publicações de dissertações e teses no banco de trabalhos do Instituto Brasileiro de informação em Ciência e Tecnologia (IBICT, 2015), ao pesquisar a relação de trabalhos que utilizam os termos riscos ambientais e vulnerabilidade. Nesse banco de dados observa-se que a partir de 2002 ocorre o aumento no número de trabalhos que utilizam os referidos termos, com ênfase na abordagem ambiental e físico-natural. No período de 2000 a 2015 foram identificados o total de124 trabalhos, sendo 15 títulos encontrados entre o período de 2000 a 2005; 40 entre 2006 a 2010 e 69 títulos no período 2011 a 2015. Os trabalhos foram desenvolvidos principalmente na área das ciências ambientais, da geografia e da saúde, em diversas universidades federais do Brasil. Entre elas destacam-se Unicamp (20 títulos), USP (15), UFMG (10), UFPE (10) e UFSC (9) em número de teses e dissertações defendidas no período de 1999 a 2015, localizadas a partir das palavras-chave riscos ambientais e vulnerabilidade.

Os termos riscos e vulnerabilidade, no contexto de desastres de origem natural, são também empregados pela mídia e pela Defesa Civil, principalmente depois das chuvas que caíram na região serrana do Rio de Janeiro em 2011, ocasionando o pior deslizamento da história do Brasil (A. Bodstein; V. V. A. de Lima; A. M. A. de Barros, 2014). De acordo com esses autores, para o secretário de Políticas e Programas de Pesquisa e Desenvolvimento do Ministério da Ciência, Tecnologia e Inovação - MCTI, do Brasil, Carlos Nobre, esse "episódio despertou a percepção brasileira para o tema dos grandes desastres". Em função dos eventos ocorridos em vários anos, em julho 2011 foi criado o Centro Nacional de Monitoramento e Alertas de Desastres Naturais (CEMADEN/MCTI) e foi reestruturado o Centro Nacional de Gerenciamento de Riscos e Desastres (CENAD/MI). Ainda nessa linha de atuação do governo federal, em 2012 foi instituído o Protocolo Nacional Conjunto para Proteção Integral a Crianças e Adolescentes, Pessoas Idosas e Pessoas com Deficiência em Situação de Riscos e Desastres, o qual tem entre os seus objetivos " [...] assegurar a proteção integral e reduzir a vulnerabilidade desses sujeitos de direito nas situações de riscos e desastres" (SDH/PR, 2013, p. 14).

No Brasil, os desastres relevantes, em âmbito nacional, identificados no período de 1991 a 2010, são do tipo estiagem e seca; inundação brusca; inundação gradual; vendaval e/ ou ciclone; tornado; granizo; geada; incêndio; movimentos de massa; erosão fluvial; erosão linear e erosão marinha (CEPED, 2012). Nas áreas urbanas, são as inundações, enxurradas e deslizamentos de encostas os eventos mais recorrentes (P. Bertoni e C. Marinho, 2013). Esses desastres no Brasil têm aumentado com o passar dos anos em função de vários fatores, entre eles o aumento da população urbana, o crescimento das cidades e a ocupação do solo urbano de maneira inadequada.

Durante as consultas realizadas no sistema online da IBICT não foram localizados nenhum trabalho referente à discussão do risco ambiental no contexto da educação básica. Portanto, a iniciativa de se levantar e discutir o tema áreas de risco e risco ambiental a partir da percepção e concepção que os sujeitos do contexto escolar têm sobre o assunto é válido e necessário, ainda que a partir de trabalho de iniciação científica e de conclusão curso, como uma discussão preliminar. Portanto, este artigo tem como objetivo retomar três TCC's e verificar a noção dos termos riscos, perigo e vulnerabilidade adotados pelos autores dos referidos trabalhos de graduação e discuti-los à luz dos autores Y.Veyret (2013), E. Marandola e D. Hogan (2006) e L. Almeida (2011). A ideia de retomar os referidos trabalhos foi o de verificar como os termos foram utilizados conceitualmente, pois verifica-se, de modo geral, uma aplicação genérica e às vezes inadequada do uso desses termos em trabalhos acadêmicos, no nível da graduação.

$\mathrm{Na}$ literatura, Risco é concebido como um elemento onipresente, como constructo eminentemente social, ou seja, é uma percepção humana (Y. Veyret, 2013; L. Q. de Almeida, 2011). Nessa vertente de pensamento Risco "é a percepção de um indivíduo ou grupo de indivíduos da probabilidade de ocorrência de um evento potencialmente perigoso e causador de danos, cujas consequências são uma função da vulnerabilidade intrínseca desse indivíduo ou grupo" (L. Q. de Almeida, 2011, p.87). A outra vertente do conceito de Risco está diretamente associada à função da combinação de dois aspectos, o perigo e a vulnerabilidade. Risco corresponde à função resultante da relação perigo verso vulnerabilidade, expresso como: $f(R)=P \times V$, na qual o “[...] P é o próprio evento perigoso (perigo) ou a sua potencialidade de ocorrência, e $V$ é a vulnerabilidade intrínseca de um indivíduo ou grupo de indivíduos" (L. Q. de Almeida, 2011, p.88). Nota-se a concepção 
de risco enquanto elemento que existe a partir da percepção das pessoas e enquanto elemento que resulta de uma função $\mathrm{P} \times \mathrm{V}$, e "caracteriza a possibilidade de que o fenômeno seja acompanhado de danos e perdas (acidente)" (L. E. S. Cerri e C. P. Amaral, 1998, p. 301). Risco existe se houver pessoas ou bens vulneráveis a um determinado perigo capaz de desencadear um acidente. 0 evento potencialmente danoso constitui o próprio perigo. Este é entendido como condição ou fenômeno com potencial de ameaçar a vida humana, a saúde, a propriedade ou os elementos da natureza, trazendo consequências desagradáveis (B. J. Fernandes e G. C. Rocha, 2007).

Riscos específicos como os ambientais são concebidos como aqueles que "resultam da associação entre os riscos naturais e os riscos decorrentes de processos naturais agravados pela atividade humana e pela ocupação do território" (Y. Veyret e Richemond, 2007, p. 63), sendo então uma noção que permite associar fatores do âmbito natural e social. Para Capri (2001), o risco ambiental compreende os demais e, portanto, constitui um termo sintético. Para outros autores, o risco ambiental abarca também os riscos naturais, os tecnológicos e os riscos sociais (L. E. S. Cerri e C. P. Amaral, 1998).

Vulnerabilidade não implica somente a existência constante da presença humana, ou de qualquer outro alvo, no local que apresenta algum tipo de perigo. Pode-se dizer que "a vulnerabilidade é uma condição externa à pessoa que a predispõe ao risco e por esta razão estão intimamente ligados, podendo mesmo ser entendidos como um existindo em função do outro" (A. Kuhnen, 2009, p.39). Vulnerabilidade é também uma noção relativa, pois está normalmente associada à ideia de "exposição aos riscos e designa a maior ou menor susceptibilidade de pessoas, lugares, infraestruturas ou ecossistemas sofrerem algum tipo particular de agravo" (H. Acselrad, 2009, p.39).

De acordo com Y. Veyret (2013), os alvos podem ser categorizados como elementos ou sistemas - população, fábricas, edificações, parques, entre outros - como alvo estrutural material - infraestrutura de transporte e serviços, por exemplo - e alvo imaterial - patrimônio cultura, rede sociais de solidariedade, entre outros. Esses alvos expostos a perigos diversos, de origem natural, social, tecnológica, econômica e política (Y. Veyret, 2013), contém implícito ou explicito situação e condição que podem refletir a possibilidade de perdas e danos material e imaterial. Ainda segundo essa autora, há diversos tipos de riscos, mas nem todos são tratados pela Geografia. Os riscos cuja percepção e gestão são acompanhadas de uma dimensão espacial, e por isso são abordados pela ciência geográfica, são classificados de acordo com os processos que os engendram. A abordagem dos riscos por áreas diferentemente da Geografia foi verificada no levantamento realizado entre as teses e dissertações no banco do IBICT (2015), mas que não cabe aqui detalhar.

De acordo com E. J. Marandola e D. J. Hogan (2004), riscos não estão circunscritos a uma dimensão da realidade, como a localização geográfica, mas exprimem toda a complexidade da sociedade contemporânea em seus diferentes embates e natureza, principalmente se discutidos no âmbito das Ciências Sociais. Nessa discussão considera-se a ideia das dimensões humanas que levam à existência do risco, para além de sua realidade local e dos componentes físicos-natural. Para os que consideram a discussão do risco à luz dos aspectos objetivos que o acompanham, como condições físiconatural e social, se fazem presentes em sua ocorrência espacial, considera-se que se existem riscos, significa que há presença de algum perigo e de vulnerabilidade a esse perigo (R. S. Dagnino e S. J. Capri Jr., 2007; F. Rebelo, 2010), que podem ser de ordem natural e, ou social. Portanto, na construção da noção de risco, a ideia de perigo e vulnerabilidade está presente, sendo que a vulnerabilidade associada ao perigo constitui o próprio fundamento do risco (Y. Veyret, 2013). Nesse princípio, risco implica na coexistência dos aspectos alvo, perigo e vulnerabilidade, sendo que a vulnerabilidade do alvo perante o perigo pode desencadear uma crise, uma catástrofe ou um acidente. Segundo A. Almeida (2011, p. 25), a noção de Risco está associada, também, a três fatores, tais como "[...] incerteza (na realização do acontecimento $e$ nas respectivas condições $e$ características de realização), Intensidade de actuação e Consequências, efeitos ou danos provocados pelo impacto nos receptores".

Discutir risco na sociedade contemporânea é importante, sejam riscos pensados na escala espacial local, regional ou global. Na escola, o ensino da Geografia pode e deve contribuir com conhecimentos para leitura do mundo, quando não fica alheio às questões inerentes ao dia a dia como, por exemplo, a questão dos riscos ambientais. Apesar disso, falar requer cautela uma vez que $o$ assunto abrange concepções e enfoques diferentes (L. R. Ayach et al., 2012), além de existirem diferentes maneiras de visualizar ou de perceber o que vem a ser um risco. Portanto, neste trabalho, a concepção de risco e de vulnerabilidade, considerada na análise e discussão dos três trabalhos escolhidos, são as apresentadas por Y. Veyret (2013).

\section{Material e método}

Neste artigo consideraram-se como material para análise três trabalhos de conclusão de curso (TCC's), cujas temáticas compreendem a questão de ambiente em espaços geográficos específicos, como o do ambiente escolar - Escola Estadual Conceição Martins de Jesus e 
Escola Municipal Secretário Humberto Almeida - e o da moradia Vila Bacuraus, na cidade de Belo Horizonte. A escolha dos referidos TCC's se apoiou na relevância da temática discutida nos trabalhos, no acesso ao material e no interesse da autora em retomar os referidos TCC's, agora à luz da discussão do uso das noções de vulnerabilidade e área de risco ambiental presentes nas referidas investigações. A releitura dos referidos TCC's implicou retomar leituras referentes à noção de riscos e vulnerabilidade, a fim de subsidiar a análise de conteúdo presente nos referidos trabalhos.

Os TCC's, que discutem os assuntos “Concepção de risco ambiental entre alunos do ensino médio; Saberes de geografia física no cotidiano da escola no contexto escolar e Percepção ambiental da população da vila Bacuraus", são identificados neste texto como trabalhos 1,2 e 3 respectivamente. Estes, que apresentam vinte (20), vinte (20) e dezesseis (16) páginas, foram desenvolvidos entre 2010 e 2011 por até três autores e se encontram em meio digital, disponível apenas na coordenação do Curso de Geografia, do Centro Universitário de Belo Horizonte (UNIBH).

Cada trabalho analisado apresenta sujeitos específicos para suas pesquisas, conforme seus objetivos de investigação. 0 trabalho 1 foi desenvolvido com alunos do $3^{\circ}$ ano do ensino médio, com idade entre 18 e 20 anos e alunos da Educação de Jovens e Adultos (EJA), idade entre 32 e 42 anos. No total foram entrevistados oito alunos, indicados pelo professor de Geografia da escola, o qual considerou como critério de escolha o interesse do aluno pela disciplina, a frequência escolar e o comportamento e concentração em sala de aula. A escolha da escola e dos alunos do $3^{\circ}$ ano ocorreu devido ao convívio com os mesmos, por parte dos autores do trabalho 1 , durante a realização de estágio supervisionado de licenciatura e por se tratar do último ano escolar dos alunos na educação básica brasileira. Esse último aspecto reforçou o interesse por conhecer a concepção que esses alunos demonstravam a respeito dos termos "riscos e áreas de riscos", representados em maquete e em seus próprios desenhos, ao término da sua educação básica.

O Ensino médio tem como objetivo, postos na Lei de Diretrizes e Bases da Educação Nacional (LDBEN), assegurar a todos os cidadãos a oportunidade de "[...] consolidar e aprofundar os conhecimentos adquiridos no ensino fundamental; aprimorar o educando como pessoa humana; possibilitar o prosseguimento de estudos; garantir a preparação básica para o trabalho e a cidadania e dotar o educando dos instrumentos que the permitam continuar aprendendo, tendo em vista o desenvolvimento da compreensão dos fundamentos científico-tecnológicos dos processos produtivos" (art. 35, incisos I a IV, LDBEN, 1996).
Os sujeitos selecionados no trabalho 2 compreenderam alunos do $9^{\circ}$ ano do ensino fundamental II. Este nível de ensino corresponde ao término da etapa de ensino fundamental com passagem para o ensino médio. No Brasil, os objetivos desses níveis de ensino são distintos. Entre os objetivos da formação, no nível fundamental, destacam-se "[...] perceber-se integrante, dependente e agente transformador do ambiente, identificando seus elementos $e$ as interações entre eles, contribuindo ativamente para a melhoria do meio ambiente; [...] questionar a realidade formulandose problemas e tratando de resolvê-los, utilizando para isso o pensamento lógico, a criatividade, a intuição, a capacidade de análise crítica, selecionando procedimentos e verificando sua adequação" (Brasil, 1999 , p. 3). Estes possibilitam trabalhar conteúdos de geografia física e o tema riscos ambientais, como conteúdos escolares capazes de auxiliarem alunos do ensino fundamental a refletirem a respeito do espaço geográfico e do espaço de vivência, tanto o escolar como os demais que fazem parte do seu cotidiano.

Já os sujeitos do trabalho 3 compreenderam moradores da Vila Bacuraus, selecionados de modo aleatório no local, durante a atividade de campo de levantamento de informações, por meio de questionário e entrevista semiestruturada. Na época foram entrevistados seis indivíduos, duas $(33,5 \%)$ pessoas que ainda viviam na vila e quatro $(66,5 \%)$ que viviam no novo conjunto habitacional da prefeitura, construído para reassentar parte da população da área de risco de inundação. A maioria $(66,5 \%)$ dos entrevistados residia há mais de 25 anos no local, sendo $16,5 \%$ há 12 anos e $16,5 \%$ há 3 anos. Todos os entrevistados, independente do tempo de moraria na vila, disseram gostar do lugar onde moram.

Os indivíduos das três pesquisas registradas nos Trabalhos de Conclusão de Curso (TCC's) apresentam perfis diferentes, mas o tema central dos referidos trabalhos refere-se a riscos e áreas de riscos ambientais, concebidos entre alunos da educação básica e moradores de uma vila revitalizada. São esses dois aspectos - tema e indivíduos - discutidos por autores distintos que interessam neste texto. Ou seja, a releitura desses três trabalhos busca responder a seguinte questão: como os autores e os indivíduos entrevistados trataram e conceberam os termos riscos ambientais, áreas de riscos e vulnerabilidade?

Para responder a essa questão foi realizado o estudo do conteúdo dos três trabalhos, referente à presença e a noção de risco ambiental e vulnerabilidade entre diferentes sujeitos. Para isso, várias leituras foram realizada sobre cada um. Na primeira, buscou-se inteirar dos objetivos, da metodologia e da organização dos trabalhos; na segunda leitura ficou-se atento a presença da discussão dos termos risco, vulnerabilidade, assim como à concepção presente em cada um. Durante a 
terceira leitura, atentou-se para os conteúdos referentes a risco ambiental e à tipologia de risco. Durante essa leitura, aproveitou-se para identificar expressões, exemplos e citações que pudessem ser aprofundados durante a análise dos dados qualitativos. Para a análise das concepções e tipos de risco expressos pelos sujeitos de cada pesquisa dos TCC's, considerou-se a abordagem da autora Y. Veyret (2013), mas sem ignorar a de E. J. Marandola e D. J. Hogan (2004).

As leituras foram acompanhadas de registros em quadros, como recurso para coleta e organização das informações qualitativas, as quais foram retomadas nos textos sempre que necessário, durante a análise do conteúdo das mesmas.

\section{Resultados e Discussão}

Devido à natureza qualitativa deste trabalho, julgouse necessário organizar o capítulo em dois itens, sendo o primeiro referente à caracterização e identificação individual dos trabalhos investigados e, no segundo, apresentar discussões específicas sobre a noção de risco e vulnerabilidade presente nos três trabalhos considerados.

\section{Conteúdo geral dos trabalhos e discussão}

\section{- Trabalho (1)}

O trabalho, cuja temática refere-se à concepção de risco ambiental entre alunos do ensino médio, especificamente alunos do terceiro ano, da Escola Estadual Conceição Martins de Jesus, realizado em 2010, levanta e discute a concepção desses alunos por meio do uso de desenhos e de maquete. $\mathrm{O}$ objetivo do trabalho foi o de investigar qual era a concepção de risco ambiental existente entre alunos, utilizando para essa investigação o recurso didático maquete. Os autores do trabalho almejavam verificar também se o recurso maquete favorecia ou não a compreensão do conceito de risco ambiental.

O trabalho foi divido em quatro partes. A primeira compreende metodologia utilizada no estudo, justificativa da utilização da maquete e o perfil socioeconômico dos entrevistados. A segunda apresenta uma revisão bibliográfica acerca das discussões relacionadas aos impactos socioambientais decorrentes da ocupação urbana, suas consequências e causas associadas aos riscos ambientais. A terceira parte analisa diferentes abordagens do conceito de risco ambiental, os termos e conceitos a ele associados e variados fatores de construção da percepção de risco ambiental. A quarta parte faz a análise dos dados e resultados, obtidos com a aplicação de questionário, com a entrevista semiestrutura, com a representação nos desenhos, elaborados pelos próprios alunos, e na maquete.
Sobre a concepção de risco ambiental, os autores (L. V. Guimarães e L. M. Pereira, 2010) mostraram que o grupo (1), alunos mais velhos (32 a 40 anos), fundamenta tal concepção na definição de degradação ambiental ocasionada pela ação humana, conforme é mostrado nas citações seguintes: "[...] a exploração inadequada do solo e a degradação da natureza"; "[...] o risco ambiental e má utilização do solo que vem causando vários tipos de erosão" e "[...] falta de recolha de lixo seletiva, pois alguns tipos de lixos contaminam o solo".

Essas análises referem-se à ideia de degradação ambiental e suas causas e não exatamente à ideia de risco ambiental, qualquer que seja a da exposição humana e de outros alvos a fenômenos naturais combinados com os sociais e tecnológicos que possam desencadear acidentes de perda de vidas e, ou bens materiais, em função da vulnerabilidade que cada um apresenta. Embora a ideia de risco ambiental encontra-se no contexto da questão ambiental, a noção de risco é diferente da concepção de degradação ambiental, conforme já apresentado no início deste texto. Essa confusão conceitual foi verificada também em outros trabalhos de graduação (L. T. Taroco, A. B. R. Ferreira e C. J. O. Souza, 2015; B. R. Ferreira e L. T. Taroco, 2014), os quais buscaram investigar também a concepção de risco e área de risco entre alunos de escolas públicas no município de São João del-Rei, no Brasil. A pesquisa realizada com alunos do fundamental Il e ensino médio, mostrou que ao se perguntar os alunos sobre o significado de risco ambiental e degradação ambiental, 40\% (ensino fundamental) e 46\% (ensino médio) disseram que os mesmos são sinônimos, outros $20 \%$ e $16 \%$ disseram que são antônimos e apenas $38 \%$ e 35\% informaram que são diferentes (L. T. Taroco, A. B. R. Ferreira e C. J. O. Souza, 2015). Ainda segundo esses autores, a mídia é a maior responsável pela informação sobre riscos ambientais, segundo as respostas apresentadas pelos alunos do ensino fundamental (80\%) e do ensino médio (75\%) de duas escolas públicas da cidade de São João del-Rei.

Os alunos mais jovens (grupo 2, com idade entre 18 e 20 anos), entrevistados no trabalho 1 , relacionaram o risco ambiental a fenômenos naturais e a situações induzidas pelo homem, as quais causam efeitos negativos sobre o próprio homem (fig.1), tais como ações antrópicas de cortes e ocupação de terrenos íngremes. Esses jovens realizaram suas representações, no formato desenho (bidimensional), antes de terem acesso à representação de área de risco em maquete. Esta traz a mesma ideia representada nos desenhos, qual seja a interação aspectos do meio físico e ocupação humano do espaço, do relevo. Portanto, pode-se afirmar que a concepção que os jovens apresentam sobre risco ambiental não foi influenciada pelo modelo na maquete, onde era possível associar as condições do relevo, o tipo de ocupação (residências, vias de acesso) e as evidências 
de intervenção antrópica no terreno (cortes e aterros no terreno e lançamento de água de servidão).

Nas respostas dos inqueridos do grupo 2 constata-se que a ideia de risco ambiental refere-se aos riscos de

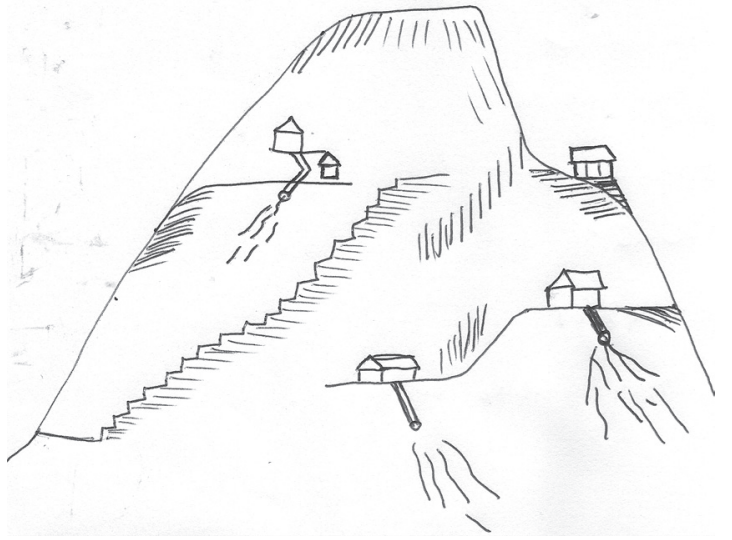

Fig.1 - Representação de área de risco de acordo com o grupo dois. (Fonte: L. V. Guimarães e L. M. Pereira, 2010).

Fig. 1 - Representation of a risk area according to group two (Source: L. V. Guimarães and L. M. Pereira, 2010).

deslizamento e inundações para a maioria dos indivíduos. $E$, de acordo com as respostas desses sujeitos (100\%) a vulnerabilidade se dá devido à localização das pessoas na área considerada de risco, conforme se observa nas frases elaboradas pelos entrevistados, ao serem questionados sobre o que entendem por vulnerabilidade: "[...] para pessoas que moram próximo ao rio por causa das enchentes"; "[...] inundação de água nas casas que estão em áreas de risco"; “[...] a estrada também porque se um carro estiver passando e estiver chovendo e cai um pedaço de terra a pessoa está correndo risco" e a "[...] construções em locais onde há deslizamentos e casas próximas ao rio e perto de estrada de rodagem". Nas citações dos alunos, a vulnerabilidade é relacionada com a localização geográfica do alvo e sua exposição ao perigo local.

Essas observações descritas pelos alunos se devem ao cotidiano vivenciado por eles na cidade, pois suas descrições apoiam no conhecimento empírico que tem sobre o cotidiano e aplicado ao assunto, uma vez que no dia a dia podem vivenciar a dinâmica e os resultados dos processos pluviais atuando nas vertentes e no fundo de vale, principalmente se tal fato ocorre no seu espaço de vivência, conforme afirma C. Souza (2010a). Nos três trabalhos analisados, as áreas de estudo apresentam tais situações, conforme descrito pelos autores do trabalho 1 .

Nos resultados do trabalho 1, constata-se, também, que a maquete é um bom recurso para ser utilizado em atividades de sondagem de conhecimento, sobre o assunto, pois permite uma visão integrada dos diferentes elementos que participam da noção de área de risco (fot. 1), condições do relevo, das edificações, da infraestrutura e do tipo de ocupação humana, no caso de área urbana.

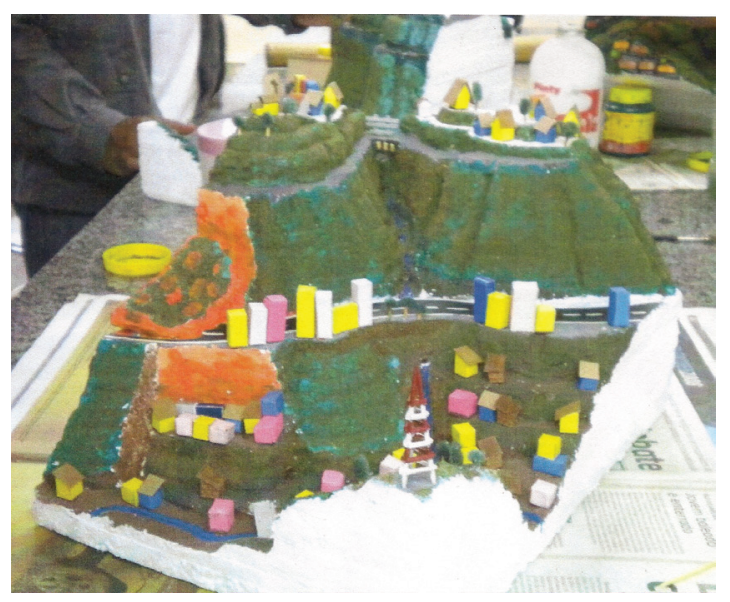

Fot. 1 - Maquete de área de risco ambiental: encosta e fundo de vale. (Fonte: L. V. Guimarães e L. M. Pereira, 2010).

Photo 1 - Model of environmental risk area: hillside and valley. (Source: L. V. Guimarães and L. M. Pereira, 2010).

- $\quad$ Trabalho (2)

O trabalho dois, que contempla o assunto "Saberes de geografia física no cotidiano da escola e potencial de risco no contexto escolar", foi realizado com professor de geografia e alunos do $9^{\circ}$ ano, da Escola Municipal Secretário Humberto Almeida, em 2010. No trabalho almejou-se verificar o que é proposto nos documentos oficiais, norteadores de conteúdos e do processo de ensino/aprendizagem para o trabalho com a disciplina de Geografia, em específico a Geografia física, na escola básica. $\mathrm{E}$, ainda, como esses conteúdos são trabalhados pelo professor de geografia, se contextualizados ou não com a realidade socioambiental do lugar onde se encontra a escola e a região onde vivem os alunos. O trabalho apresenta revisão sobre os conteúdos de geografia física em documentos oficiais, como Parâmetros Curriculares Nacionais/PCN'S (Brasil, 1999) e Proposta Curricular da prefeitura de Belo Horizonte/ MG (Belo Horizonte, 2009), para os conteúdos de geografia, voltados para alunos do $9^{\circ}$ ano.

Os autores (B. F. Santos; C. O. Rocha e V. B. dos Santos, 2010) do referido trabalho abordaram, também, a importância dos conteúdos da geografia física, com perspectiva para a abordagem ambiental na escola básica e, ainda, os aspectos socioambientais do espaço geográfico da Escola Municipal Secretário Humberto Almeida. No item referente aos resultados e discussões, o trabalho contém uma análise sobre a geografia física presente na prática do professor do $9^{\circ}$ ano. De acordo 
com os resultados apresentados, o professor utiliza muito pouco nas suas aulas os elementos sociais, culturais, econômicos e ambientais presentes na área envolvente $e$ na região onde se encontra a escola.

Na região da escola existem áreas invadidas e ocupadas de forma irregular, dois conjuntos habitacionais, sendo formados por prédios e outro por casas populares e, ainda, existe próximo grande área contendo vegetação do tipo Cerrado. Além disso, existe na área a confluência de dois cursos d'água, o ribeirão do Onça que recebe o Córrego Isidoro e continua drenando na direção Nordeste. A escola fica exatamente na porção entre os dois cursos, próximo à confluência (fot. 2), nas proximidades existe uma estação de tratamento de esgoto do Ribeirão do Onça.

O ambiente da área escolar apresenta potencial a ser explorado. Este contexto apresenta canais fluviais com aspectos relevantes e com potencial para serem explorados no âmbito da geografia física e das áreas de risco ambiental (Fot.2). Entre os aspectos estão características morfológicas dos leitos maior, menor e vazantes dos dois canais que circundam a escola e desaguam em confluência o sul da área escolar. Durante o período de chuvas, que ocorre no verão, entre os meses de dezembro e março, o nível das águas extrapola o leito menor e atingem a planície de inundação, em parte ocupada. $\mathrm{O}$ aumento do volume no canal se deve às chuvas concentradas nas cabeceiras e, principalmente, ao escoamento superficial sobre solos impermeáveis.
Sabe-se que a impermeabilização dos espaços de circulação e a falta de infiltração contribuem para o fato da ocorrência de inundações (F. Rebelo, 1994), em diversas partes do mundo. 0 escoamento concentrado sobre as vertentes impermeabilizadas e ocupadas com vias de circulação, edificações favorece o acúmulo de água no fundo do vale. Em vários pontos verificamse entradas das galerias das águas pluviais entupidas com lixo, sacolas e garrafas plásticas descartadas aleatoriamente nas ruas e calçadas.

Esses aspectos podem ser trabalhos em sala e em visita de campo, com atenção especial para as condições da dinâmica fluvial, a ocupação do solo e o descaso com o lixo doméstico e entulhos restantes de obras da construção civil. Muitos problemas observados no espaço urbano se devem à falta de colaboração da própria população, combinada com as más condições da infraestrutura pluvial, da coleta de lixo e ações dos governos locais, principalmente em países social e economicamente desfavorecidos. Isso não significa dizer que em países economicamente riscos não ocorram problemas urbanos e riscos ambientais. De acordo com A. Monteiro (1994), face ao tipo de problemas e às principais causas de degradação do meio ambiente em diversas cidades europeias, a Comunidade Europeia definiu um conjunto de orientações fundamentais, tais como coordenação-integração do desenvolvimento econômico e da política social; da responsabilização do indivíduo, da empresa e da administração pública pelos impactos ocasionados no ambiente urbano.
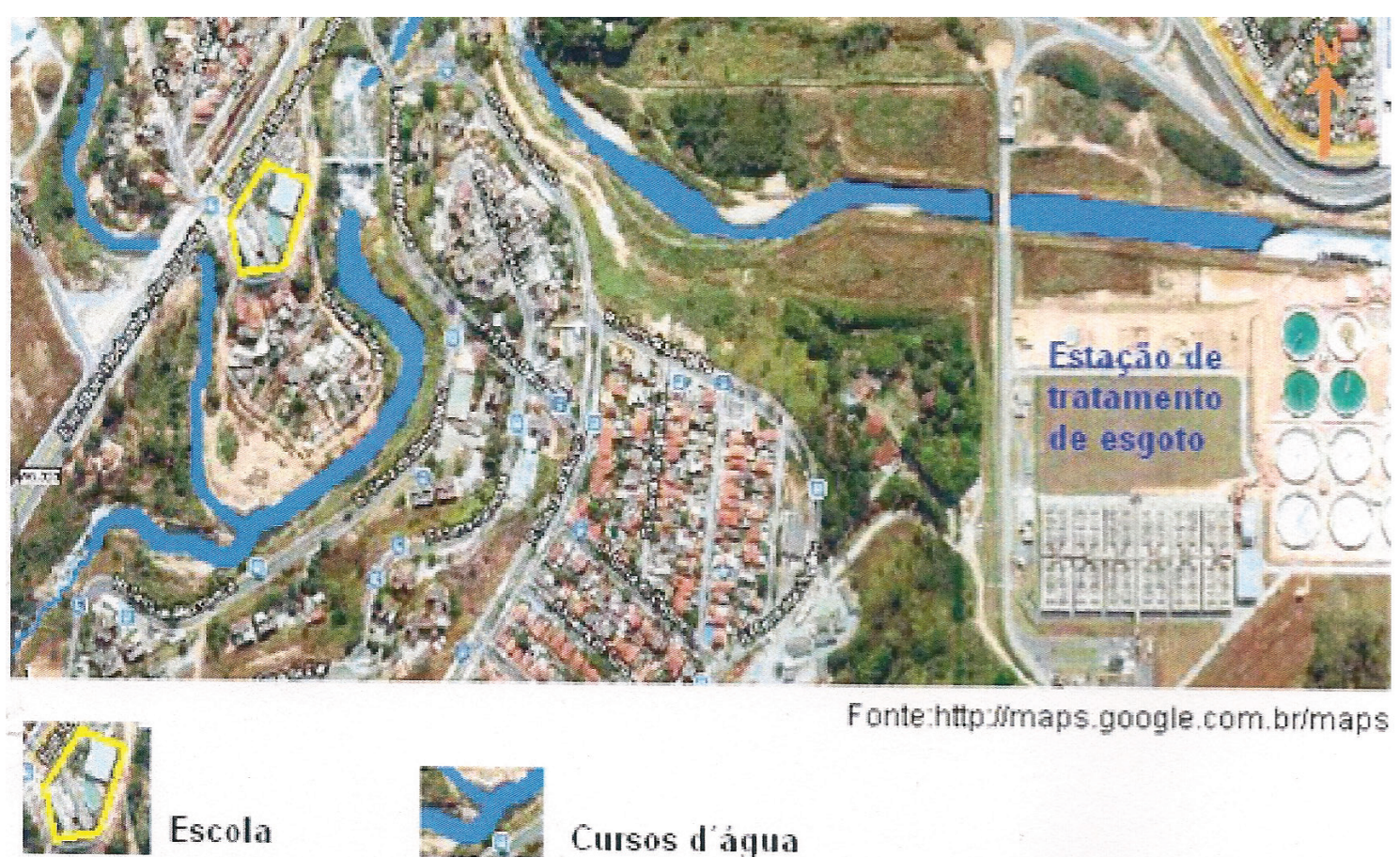

Fonte httpumaps google.com brimaps 
No entorno da escola, é possível trabalhar também a diversidade de tipo de uso do solo, o que apresenta diferentes tipos de alvos e de condições de vulnerabilidade em função da infraestrutura, da posição geográfica como base na discussão de Y. Veyret (2013) e da percepção do risco por parte de diferentes sujeitos. Se o professor quiser extrapolar a noção de risco para além dos aspectos empíricos, levando em consideração a questão social, econômica e política, como discutido por E. J. Marandola e D. J. Hogan (2004), estes aspectos da região também possibilitam.

A geografia escolar tem por função contribuir para a construção de conhecimentos significativos para a vida das pessoas. Isso significa que, os conteúdos trabalhados na geografia escolar devam contribuir com os alunos no seu dia a dia, de modo que eles possam fazer uma leitura e interpretação do mundo, da realidade. Sendo assim, é importante ter em mente que a prática de ensinar geografia tem que ser baseada no cotidiano dos alunos.

Além do potencial de estudo da região escolar e do espaço de vivência dos alunos, os documentos oficiais apresentam eixos temáticos nos quais se encaixa o tema de riscos ambientais. Os eixos, 1 - Relação Sociedade e Natureza e 5 - Questões Socioambientais e Sociedade Sustentáveis, de acordo com o documento da Prefeitura de Belo Horizonte (B. Santos et al., 2010), compreendem os conteúdos da geografia física.

Nos PCN'S, o eixo 3 - Modernização, modos de vida e a problemática ambiental, o qual se desdobra em subeixos: - Ambiente urbano, indústria e modo de vida; - O Brasil diante das questões ambientais; - Ambientalismo: pensar e agir, entre outros temas - possibilita considerar a questão do risco ambiental e da questão ambiental, de trabalhar com o subeixo "Ambiente urbano, indústria e modo de vida". A partir do referido subeixo é possível discutir as seguintes temáticas: - Ocupação de áreas de risco ambiental: alagadiços, encostas etc.; - Impacto de impermeabilização do solo nas Cidades e os efeitos na drenagem. E, também, nos documentos do PCN'S, referentes a $6^{\circ}$ ao $9^{\circ}$ ano, existem 34 itens no $P C N$ de Geografia, 07 no de Ciências e 12 no de Meio Ambiente, dando destaque aos temas referentes à Ocupação de áreas de risco: alagadiços, encostas, etc. e Políticas públicas urbanas - planos diretores, infraestrutura e a cidade apartada. E, em relação às séries do Ensino Médio, foram encontrados 16 itens no PCN de Biologia, 03 no de Química e 03 no de Geografia, dando destaque a: Avaliar as condições ambientais, identificando o destino do lixo e do esgoto, o tratamento dado à água, o modo de ocupação do solo, as condições dos rios e córregos e a qualidade do ar (L. Baeta e N. Morais, 2014).

Essas temáticas possibilitam trabalhar várias questões referentes à dinâmica da natureza e da sociedade, tais como: Por que ocorrem deslizamentos? Como ocorrem as enchentes e inundações? O homem é um agente modelador do espaço geográfico? Quais são as condições físico-naturais e sociais do ambiente escolar?

Nota-se que os eixos presentes nos documentos oficiais - nacional e municipal - indicam importância de se trabalhar a questão ambiental, considerando a interação cidade, urbano, industrialização, elementos da natureza, ocupação do espaço, consequências socioambientais. Apesar de esses documentos não indicarem a questão da problematização das áreas de riscos ambientais, presente no contexto da paisagem considerada, os professores de geografia podem e devem considerar essa perspectiva também, principalmente quando se considera a categoria paisagem e lugar, conforme já foi considerado por C. Souza (2013), em outros trabalhos.

A paisagem compreende o domínio visível de um espaço, o domínio do aparente e de tudo que a visão alcança (L. S. Cavalcanti, 2006), ela é vivida e percebida pelos habitantes da cidade no seu cotidiano. As áreas de risco ambiental podem não ser apreendidas inicialmente pela aparência objetiva da paisagem, mas podem apresentar elementos como cicatrizes de erosão, de deslizamento, marcas de inundações, as quais possibilitam aos olhos do observador, consciente desses elementos, captarem tais áreas no contexto da paisagem. Esses elementos são entendidos pelos geógrafos físicos como evidências de processos geomorfológicos e hidrológicos. Essas evidências referem-se à presença de perigos iminentes, que podem ser captados pelo lance de visão sobre a paisagem investigada durante visita em campo (C. Souza, 2013). Por isso, a importância de se conhecerem os aspectos físicos do relevo, mas principalmente seus processos e dinamismo, no entendimento da noção de risco ambiental.

\section{- Trabalho (3)}

0 trabalho três, referente à Percepção ambiental da população da vila Bacuraus, teve como objetivo verificar a percepção sobre riscos ambientais dos moradores da referida comunidade e a relação que eles têm com o lugar onde moram. 0 trabalho desenvolvido em 2011, elaborado por A. M. Farah e R. C. Quintão (2011), apresenta como instrumento de pesquisa entrevista semiestruturada, visita a campo e estudo de imagens aéreas em períodos distintos. Na pesquisa consideraram-se os conceitos de percepção ambiental e áreas de risco, fundamentados em Y. Tuan (1980) e A. Kuhnen (2009). Além das leituras sobre o tema e conceitos, o trabalho contém item dedicado à descrição e caracterização da Vila Bacuraus, referente aos anos de 1999, 2005 e 2011, os quais correspondem às datas antes, durante e após implantação de saneamento e infraestrutura urbana (fot.3 e fot. 4), promovida pela prefeitura de Belo Horizonte. 
Em 1999, a vila Bacuraus correspondia a um aglomerado de pequenas casas de alvenaria, localizadas às margens do córrego (Fot. 3) de mesmo codinome, Bacuraus. Entre 1999 e 2005, esse aglomerado de casas deu lugar à via de circulação, praça, área com vegetação rasteira ao longo das margens e saneamento básico local (fot. 4). A população, constituída por 90 famílias foi retirada e relocada em conjunto habitacional construído para receber os moradores mobilizados das margens do Córrego Bacuraus. Desde a criação do Programa Estrutural em Área de Risco (Pear), em 1994, o número de edificações em situação de risco alto e muito alto nas vilas e favelas foi reduzido em $80 \%$. Em 1994, eram 14.349 e em 2014 são 2.219 (PBH, 2014).

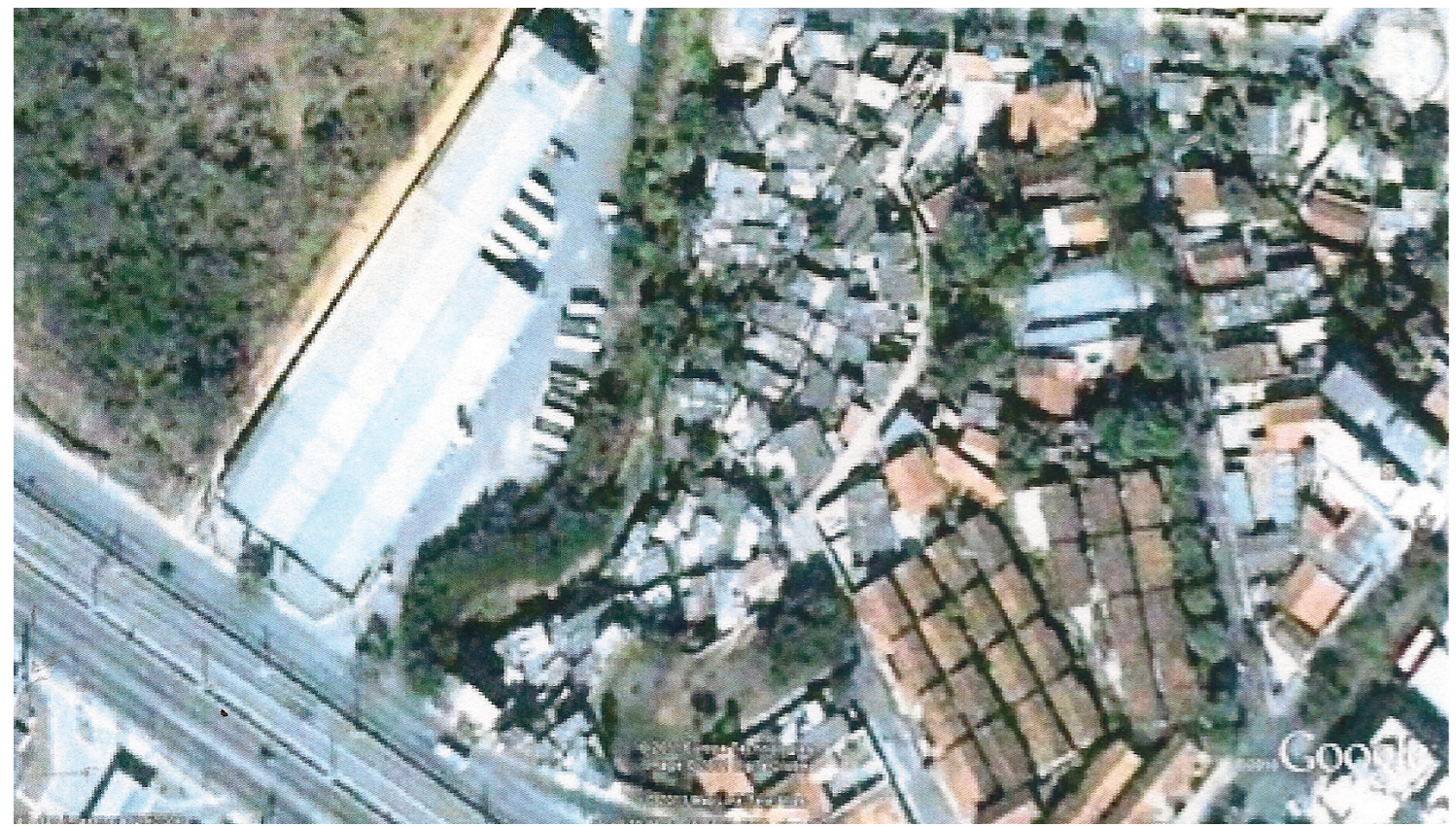

Fot. 3 - Imagem de satélite da Vila Bacuraus em 1999. (Fonte: A. Farah e R. Quintão, 2011).

Photo 3 - Satellite image of Bacuraus Village in 1999. (Source: A. Farah and R. Quintão, 2011).

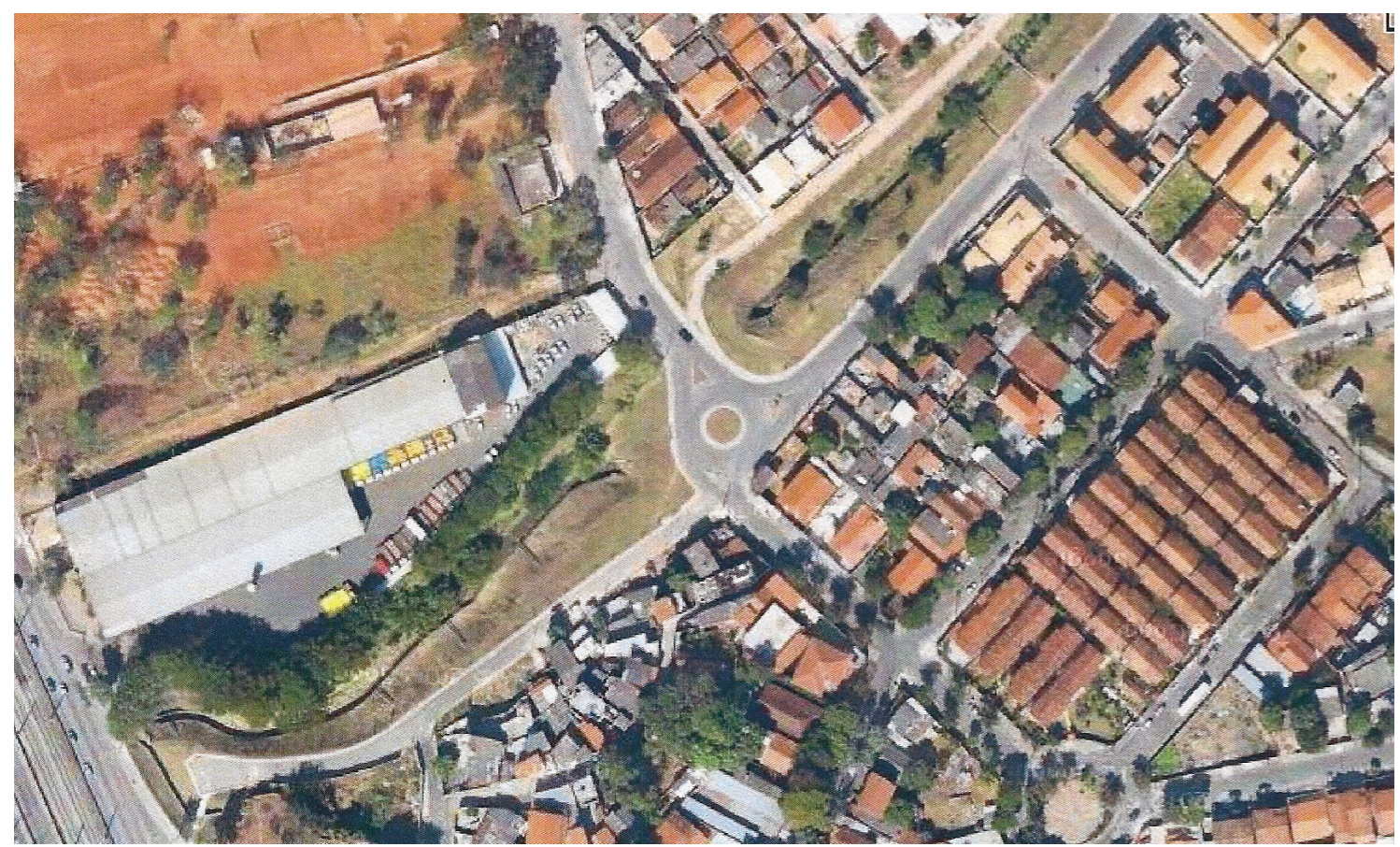

Fot. 4 - Imagem de satélite da Vila Bacuraus em 2011. (Fonte: A. Farah e R. Quintão, 2011).

Photo 4 - Satellite image of Bacuraus Village in 2011. (Source: A. Farah and R. Quintão, 2011). 
De acordo com o trabalho 3 , no item resultados da pesquisa, verifica-se que $83,3 \%$ das pessoas entrevistadas reconheceram, em fotografias, situações de áreas de risco, apontadas como risco de cheias e desmoronamento. Apesar de as pessoas apresentarem noção sobre o que seja área de risco e reconhecerem em sua vila, no passado, e nas fotografias áreas de risco, todas disseram que vivia na Vila Bacuraus devido a vários motivos, entre eles o tempo de moradia no lugar, a infraestrutura existente no entorno e os tipos de serviços próximos, independente da existência do risco. Segundo Y. F. Tuan (1980) no meio em que vive a pessoa existem elementos subjetivos e pessoais que acabam criando um vínculo afetivo do individuo pelo lugar, ainda que esse lugar não seja um local adequado para se viver.

Na época de 2011, a Vila Bacuraus já havia passado por um processo de reassentamento das 90 famílias que viviam em situação de risco. Elas foram retiradas em 2008 através de um Plano de Diretrizes de Remoção e Reassentamento, para que ocorresse, na região, a urbanização da Avenida Bacuraus. Devido a essa ação de remoção da população da área de risco, $100 \%$ das pessoas entrevistadas disseram que hoje não existem casas em área de risco no local onde vivem. 0 perigo de inundação do canal ainda existe, apesar das intervenções das obras de engenharia, mas com frequência e magnitude muito menor se comparada com o período anterior às obras. Essa situação de obras de engenharia, mais a distância do limite máximo das cheias, fazem com que a vulnerabilidade dos alvos que permaneceram no local seja baixo, o que leva à não existência do risco alto de inundação, à luz da concepção da existência da tríade: perigo, alvo e vulnerabilidade como discutido por Y. Veyret (2013). Essa lógica, não foi apresentada pelos sujeitos entrevistados, mas todos disseram que depois das obras deixaram de existir casas em área de risco na Vila Bacuraus.

\section{Discussão dos termos risco e vulnerabilidade nos trabalhos}

Cada um dos trabalhos analisados contemplou a questão "Risco" de maneira direta ou indiretamente nas suas pesquisas, as quais consideraram abordagens do tema pelas perspectivas da percepção ambiental, concepção de riscos e saberes escolares.

Os trabalhos um (1) e três (3) contemplaram a questão do "Risco" de maneira direta, ao fazerem perguntas e abordagens sobre o assunto aos seus entrevistados. Em ambos, a ideia de risco refere-se à questão da combinação da presença humana próximo a canais de drenagem e, ou ocupando encostas. A noção de risco ambiental, que considera a perspectiva de ocupação do espaço pela população, a interação dos efeitos dessa apropriação e dos fenômenos naturais revelam que os sujeitos entendem a existência dos efeitos dessas relações, traduzidos como risco para a população. Por outro lado, revela também a falta de clareza entre os termos risco, perigo, vulnerabilidade que antecedem a ideia de área de risco. Essa confusão conceitual entre as pessoas já foi identificada por L. Q. de Almeida (2011) em um de seus trabalhos.

A ideia de vulnerabilidade como sendo a da exposição geográfica do alvo ao perigo foi a única presente na discussão dos trabalhos (1) e (3). Essa ideia pode ser considerada, mas sabendo da existência de outras abordagens mais analíticas e até quantitativa, se for esse o caso.

O trabalho dois (2), apesar de não ter como foco a questão de área de risco, quando aborda os conteúdos de geografia física na escola básica e os saberes do professor, revela dentro da questão ambiental, a ser explorado pela geografia escolar, condições da dinâmica fluvial e a existência de áreas de risco junto à escola. Esse risco se deve à interação dos aspectos, alvo, perigo e vulnerabilidade como é colocado por Y. Veyret (2013). A vulnerabilidade, indicada nesse caso, relaciona-se com a localização geográfica dos alvos, assim como apontado, também, pelos sujeitos das pesquisas (1) e (3).

Em todos os trabalhos nota-se que a ideia de vulnerabilidade apoia-se principalmente como exposição direta do alvo ao perigo local, como encostas íngremes e inundações dos cursos d'água, comuns no caso brasileiro e em Belo Horizonte. Essa ideia corresponde a uma das possibilidades de se entender o conceito de vulnerabilidade, o qual é amplo evariado. ParaA. Dauphiné (2001) apud Y. Veyret (2013, p.393), vulnerabilidade "exprime o grau das consequências previsíveis geradas por um fenômeno natural e que podem afetar o alvo". Noutras definições vulnerabilidade é entendida como, "[...] a determinação dos danos máximos em função de diversos usos do solo e dos tipos de construção: em caso de inundação, uma casa construída com um entressolho não apresenta o mesmo grau de vulnerabilidade que uma construção sem essa arquitetura, cujo andar térreo habitado está inteiramente exposto à álea" (Y. Veyret, 2013, p.40).

Nota-se que nas definições a vulnerabilidade compreende a análise estimativa dos danos potenciais que podem afetar o alvo e não somente a exposição geográfica do alvo. $\mathrm{Na}$ análise presente são levados em consideração outros aspectos como ausência ou não de infraestrutura, condições estruturais das edificações, a capacidade de resposta institucional, condições socioeconômicas da população alvo (Y. Veyret, 2013) e à própria representação de risco por parte dos sujeitos e o conhecimento sobre o assunto. De acordo com Y. Veyret (2013), uma verdadeira educação sobre os riscos é capaz de reduzir a vulnerabilidade. 
Em linhas gerais, pode-se dizer que a existência de diferentes tipos de análise da questão riscos mostra a possibilidade de abordagens diversas sobre o tema, podendo ser destacados aspectos do campo da natureza e, ou do social. Nesses campos, a convergência e o entrelaçamento das ciências naturais e sociais apresentam potencial de discussão que recai no campo da Geografia, à luz da interação Sociedade/Natureza e Riscos (C. Souza, 2013). Essa perspectiva constitui campo fértil para a Geografia, principalmente a escolar.

É necessário que a Geografia, por meio da temática "risco ambiental", propicie ao aluno subsídios para a compreensão da realidade e das questões ambientais ali postas pela sociedade em interação com a natureza, através de uma contextualização capaz de provocar no aluno mudança de atitude, que forme no sujeito uma postura de cidadão, tornando-o crítico e atuante na sociedade em que vive. Qualquer intervenção de ensino para a aprendizagem deve partir do conhecimento e entendimento que os alunos apresentam sobre o tema ou o conceito em discussão, principalmente quando essa aprendizagem refere-se à leitura do mundo.

\section{Conclusão}

A discussão sobre importância e o papel social da Geografia na escola básica se faz presente na formação de professores de geografia, em diferentes contextos acadêmicos e se revela em estruturas curriculares, bem como em produções acadêmicas no âmbito da iniciação científica, do PIBID (Programa Institucional de Bolsa de Iniciação à Docência) e dos trabalhos de conclusão de curso (TCC). A importância social da Geografia na escola básica se constitui quando esse campo do conhecimento possibilita aos sujeitos alunos entenderem e lerem a dinâmica e construção do espaço geográfico, atentos a fatos e fenômenos que ocorrem em diferentes escalas espaciais e temporais. A questão do risco, em específico o risco ambiental, constitui um fato presente no cotidiano das pessoas, principalmente para as residentes no espaço urbano.

A análise e discussão de trabalhos elaborados como TCCs mostraram que existem interesses de graduandos pela discussão da temática "riscos ambientais" pela perspectiva geográfica, tanto no âmbito do estudo de caso, como aconteceu com o trabalho na Vila Bacuraus, quanto no âmbito da geografia escolar. Neste âmbito, os conteúdos presentes na temática mostraram possibilidades didático-pedagógicas, como o estudo de área em volta da escola, por meio do método estudo do meio, de visita orientada, ou de pesquisa e trabalhos com fotografias e imagens de satélites disponíveis na internet, como as do Google, entre outras.
O levantamento e análise dos conteúdos e da temática em trabalhos de conclusão de curso (TCCs) trouxeram à tona, durante diálogos sobre riscos e educação no interior deste trabalho, a importância e a necessidade de se considerar a temática "riscos ambientais" no contexto escolar, principalmente pelos caminhos da geografia, ciência que lida com conhecimentos referentes às dimensões da natureza e da sociedade. A retomada desses TCCs possibilitou, também, constatar que os autores ao optarem trabalhar com o tema "riscos" e "risco ambiental", associados aos estudos escolares ou estudo de caso, realizaram leituras gerais sobre o referido tema, atentando-se para definições de alguns autores, não constituindo uma revisão bibliográfica sobre o assunto. Esse fato é compreensivo quando se leva em consideração que outras definições e temas também foram considerados nos trabalhos, relacionados ao campo da educação como saberes, geografia escolar ou das ciências sociais, como a percepção.

A iniciativa para se trabalhar de maneira aplicada tal tema a estudo de caso e ou a propostas escolares é bem vinda e deve ser estimulada. Mas, é necessário que mais leituras sobre o tema "riscos" sejam realizadas. Essas leituras e discussões no âmbito acadêmico ainda são recentes e limitadas a alguns cursos de graduação em Geografia. Acredita-se que a iniciativa de eventos como o III Congresso Internacional, I Simpósio Ibero-americano, II Encontro Luso Brasileiro de Riscos contribua para que mais leituras e discussões sobre a temática "Riscos" sejam ampliadas e aprofundadas e estendidas ao contexto mineiro e possivelmente brasileiro.

\section{Referências bibliográficas}

Acselrad, Henri (2006). Vulnerabilidade ambiental, processos e relações. In II Encontro Nacional De Produtores E Usuários De Informações Sociais, Econômicas e Territoriais. Rio de Janeiro: FIBGE. Disponível em: http://www.ibcperu.org/doc/isis/11342.pdf.

Almeida, Lutiane Q. de (2011). Por uma ciência dos riscos e vulnerabilidades na geografia. Mercator, Fortaleza, v. 10, n. 23, p. 83-99.

Almeida, Antônio B. de. (2011). Risco e gestão do risco. Questões filosóficas subjacentes ao modelo técnico conceptual. Territorium, n.18; p. 23 - 31. Disponível em: http://uww.uc.pt/fluc/nicif/riscos/Documentacao/ Temitorium/T18_artg/Antonio_Betamio_de_Almeida.pdf.

Ayach, Luci R., Guimarães, Suzana T. de L., Cappi, Nanci e Ayach, Carlos (2012). Saúde, saneamento e percepcão de riscos ambientais urbanos. Caderno de Geografia. Belo Horizonte: Pontifícia Universidade Católica (PUC-MG), v.22; n.37, p.47- 64.

Baeta, Lucilene de F. e Morais, Natália L. (2014). Educar para prevenir: proteção e defesa civil nas escolas por um currículo escolar vivo. Campinas: Terrae Didatica, 10-3, p.336-345.

Belo Horizonte (2009). Proposicões Curriculares Ensino Fundamental Geografia $3^{\circ} \mathrm{Ciclo}$ - Rede Municipal de Belo Horizonte. Texto Preliminar. Belo Horizonte: PBH.

Bertoni, Pedro e Marinho, Clarice. Gestão de riscos e resposta a desastres naturais: a visão do planejamento. In: VI Congresso CONSAD de Gestão Pública. Brasília, abr. 2013. (Painel 19/069). 
Bodstein, Airton, Lima, Valéria A. de e Barros, Ângela. M. A. de. (2014). A vulnerabilidade do idoso em situações desastres: necessidade de uma política de resiliência eficaz. Ambiente \& Sociedade. São Paulo v. XVII, n 2; p. 157-174

Brasil, Secretária de Educação Fundamental (1999). Parâmetros Curriculares Nacionais: História e Geografia. Secretaria de Educação Fundamental. Brasília: MEC/SEF.

Cavalcanti, Lana de S. (2006). Bases teórico-metodológicas da Geografia: uma referência para a formação e a prática de ensino. In Cavalcanti, L. de S. (org.). Formação de professores: concepções e Práticas em geografia. Goiânia: Editora Vieira, p.27-49.

CEPED. Atlas brasileiro de desastres naturais 1991 a 2010: volume Brasil. Florianópolis: CEPED UFSC, 2012. Disponível em: http://150.162.127.14:8080/ atlas/ Brasil\%20Rev.pdf. Acesso em 04 set. 2015.

Cerri, Leandro E. da S. e Amaral, Cláudio, P. do. (1998). Riscos geológicos. In Oliveira, Antônio $M$. dos S. e Brito, Sérgio N. A. de. Geologia de Engenharia. São Paulo: ABGE, cap. 18, Riscos geológico, p. 301 a 310.

Dagnino, Ricardo de S., Capri Jr., Salvador (2007). Risco ambiental: conceitos e aplicações. Climatologia e Estudos da Paisagem. Rio Claro, v.2, n.2, p. 50-87.

Dauphiné, André (2001). Risques et catástrofes: observer, spatialiser, compreendre, gérer. Paris: Armand Colin, Coll.

Farah, Aline M. e Quintão, Renata C. (2011). Um estudo sobre a percepção ambiental da população da região da Vila Bacuraus. Belo Horizonte: UNIBH, (Trabalho de conclusão de curso. Geografia), 16 p.

Fernandes, Bruno de J. e Rocha, Geraldo C. (2007). Educação sobre riscos ambientais: uma proposta metodológica. Virtú (UFJF), v. 4, p. 01-15.

Guimarães, Lucas V. e Pereira, Luciana M. (2010). Levantamento da concepção de risco ambiental entre alunos de geografia do ensino médio por meio do uso de maquete. Belo Horizonte: UNIBH, (Trabalho de conclusão de curso. Curso de Geografia), 20 p.

IBICT - INSTITUTO BRASILEIRO DE INFORMAÇÃO EM CIÊNCIAS E TECNOLOGIAS (2015). Biblioteca digita brasileira de teses e dissertações. http://bdtd.ibict.br/ vufind/. Acesso em 12 de out. 2015

Lei 12.608 , de 10 de abril de 2012. Dispõe sobre o Sistema Nacional de Proteção e Defesa Civil SINPDEC e o Conselho Nacional de Proteção e Defesa Civil - CONPDEC, autoriza a criação de sistema de informações e monitoramento de desastres e dá outras providências. Disponível em: http://www.planalto.gov.br/ccivil_03/_ Ato2011- 2014/2012/Lei/L12608.htm. Acesso em: 14 out. 2015.

LDBEN - LEI DE DIRETRIZES E BASES DA EDUCACÃO NACIONAL. (1996). LEI No 9.394, DE 20 DE DEZEMBRO DE 1996. http://www.planalto.gov.br/ccivil_03/ Leis/L9394.htm. Acesso em 12 de out. de 2015.

Kuhnen, Ariane (2009). Meio Ambiente e vulnerabilidade. A percepção ambiental de risco e o comportamento humano. Geografia. Londrina, v.18, n.2, p. 37 - 52. http://www.uel.br/revistas/uel/index. php/geografia/issue/view/315/.
Marandola Jr., Eduardo e Hogan, Daniel Joseph (2006). 0 Risco em perspectiva: tendências e abordagens. In: Anais do II Encontro ANPPAS Associação Nacional de Pós-Graduação e Pesquisa em Ambiente e sociedade, p.1-25.

Monteiro, Ana. A climatologia como componente essencial no diagnóstico e na avalição dos impactos ambientais em espaços urbanizados. 0 caso da cidade do Porto. Territorium, n. 1, p.17 - 22.

PBH - PREFEITURA MUNICIPAL DE BELO HORIZONTE (2014). Sala de notícias. http://portalpbh.pbh.gov.br/ $\mathrm{pbh} / \mathrm{ecp} /$ noticia.?evento=portlet \&pAc=not\&i $\mathrm{dConteudo}=176958 \& \&$ pldPlc $=\&$ app $=$ salanotici as. Acesso em 14 out. 2015.

Rebelo, Fernando (2010). Geografia física e riscos naturais. Coimbra, Universidade de Coimbra.

Rebelo, Fernando (1994). Do ordenamento do território à gestão dos riscos naturais. A importância da Geografia Física salientada através de casos de estudos selecionados em Portugal. Territorium, n. 1, p.7 - 15. Disponível em: http://www. uc.pt/fluc/nicif/riscos/Documentacao/ Territorium/T01_artg/T01_artg01.pdf.

Santos, Bruno F. dos, Rocha, Charles O. e Santos, Varlei B. dos (2010). Saberes da Geografia física no cotidiano da escola. Belo Horizonte: UNIBH, (Trabalho de conclusão de curso. Geografia), $20 \mathrm{p}$.

SDH/PR - SECRETARIA DE DIREITOS HUMANOS DA PRESIDÊNCIA DA REPÚBLICA (2013). Protocolo nacional conjunto para proteção integral a crianças $e$ adolescentes, pessoas idosas e pessoas com deficiência em situação de riscos e desastres. Brasil: SDH/PR, set., 104p. Disponível em http: / /www.sdh.gov.br/assuntos/criancas-eadolescentes/protocolo-de-desastres/pdfse-docs/protocolo-de-protecao-integral-emsituacao-de-riscos-e-desastres. Acesso em 10 de out. 2015.

Souza, Carla J. O. (2013). Área de risco socioambiental nas cidades: prática educativa na formação docente e na geografia escolar. In: VI Congresso Ibérico de Didática de Geografia. Anais do VI Congresso Ibérico de Didática de Geografia Porto, Portugal, p. 563-575.

Souza, Carla. J. O. (2010 a). Dinâmica do relevo no estudo geográfico urbano: discussão teórica e prática. In: VI Seminário latino-americano de geografia física, Il Seminário ibero-americano de geografia física. Universidade de Coimbra. Coimbra.

Tarôco, Larissa. T., Ferreira, André. B. R., Souza, Carla. J. O. (2015). Geografia e educação para o risco: uma abordagem possível. Revista Territorium Terram. São João del-Rei: UFSJ, v.03, p.49 - 53.

Tuan, Yi-Fu (190). Topofilia: um estudo da percepção, atitudes e valores do meio ambiente. São Paulo: Difel.

Veyret, Yvette (2013). Os riscos - o homem como agressor e vítima do meio ambiente. São Paulo: Contexto.

Veyret, Yvette, Richemond, Nancy M. (2007). O Risco, os riscos. In: Veyret, Yvette (Org.) Os Riscos - Homem como agressor e vítima do meio ambiente. São Paulo: Contexto, p. 23-79. 

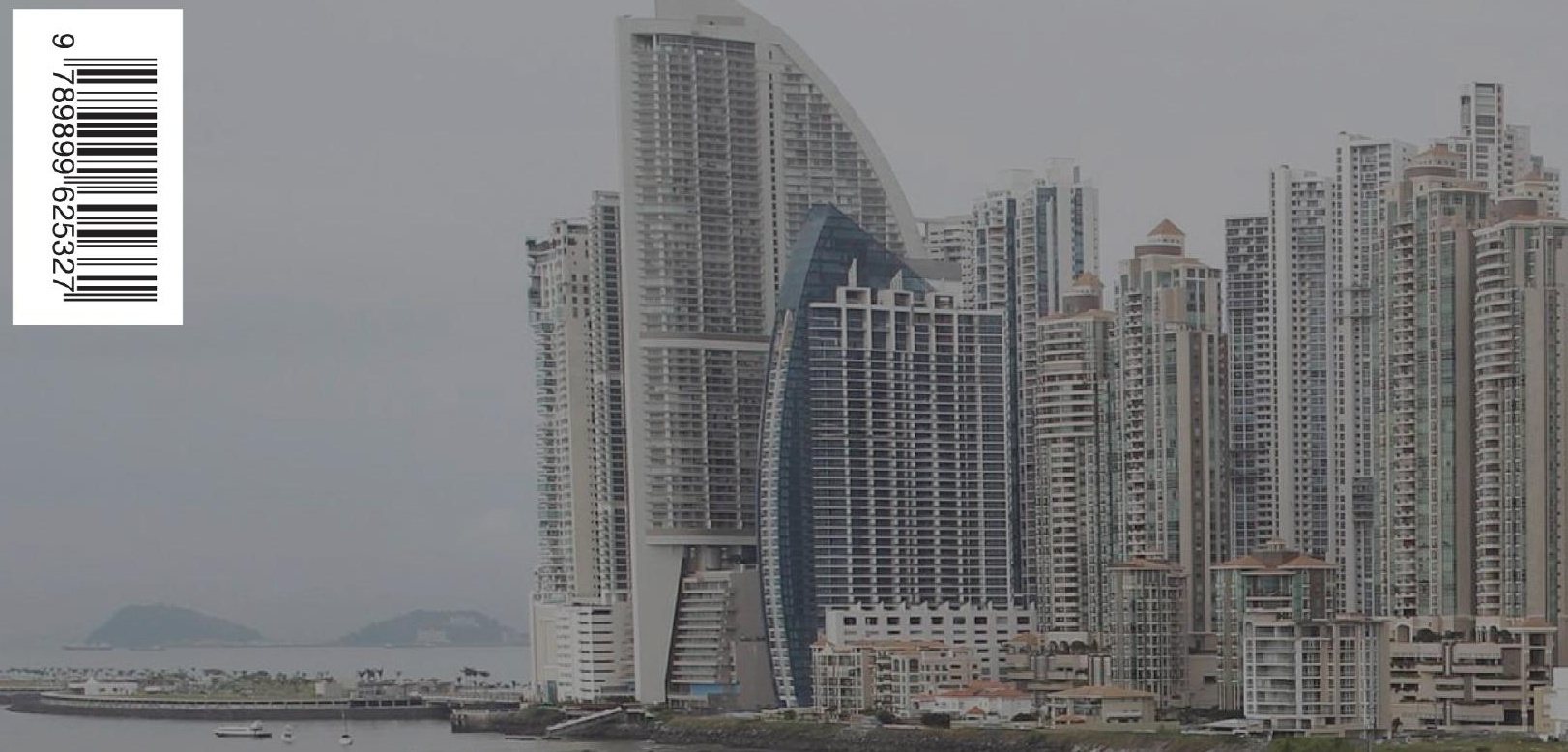

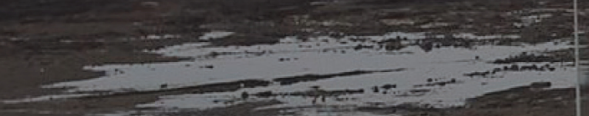

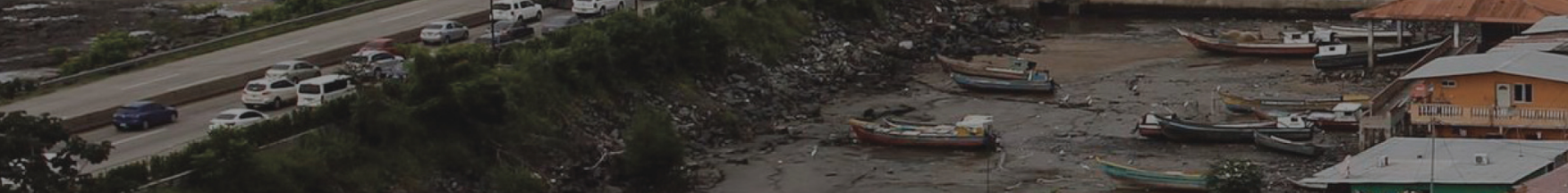

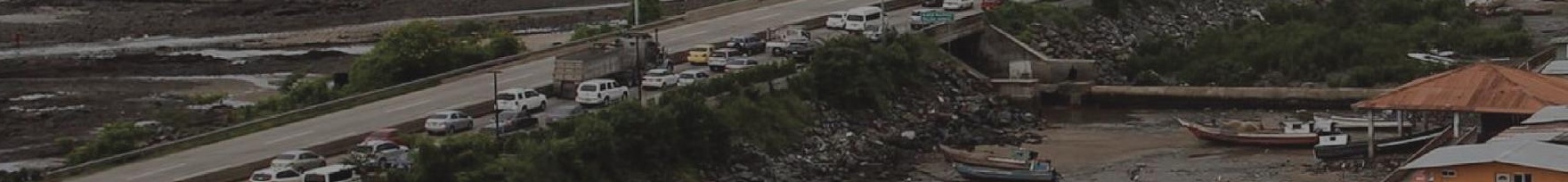
inse- $n=$ Riscos I I I

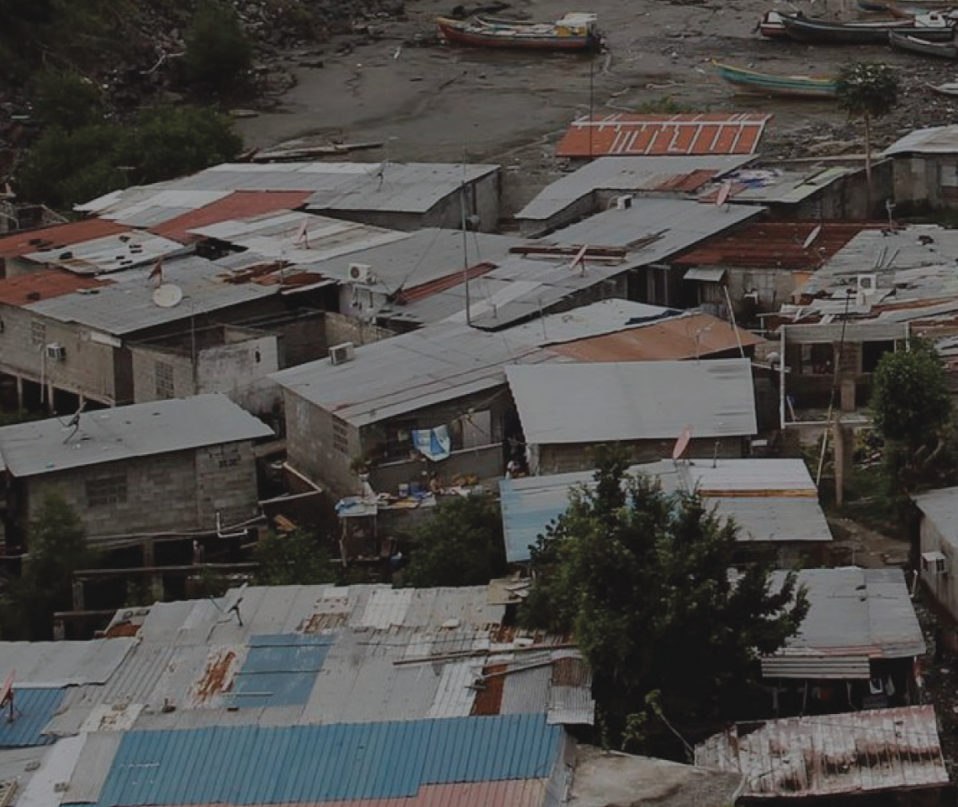

